\title{
A Quantitative Microscopic Analysis of the Myocardial Interstitial Tissue Space and Myocardial Fiber Diameter in Rats with Vitamin $E$ and Selenium Deficiency
}

\author{
Jami G. Shakibi, M.D., F.A.C.C. and William L. Stone, Ph.D.
}

\begin{abstract}
SUMmary
Vitamin E (E) and selenium (Se) are important antioxidant nutrients, preventing membrane damage by lipid hydroperoxides. In a previous study on $\mathrm{E}+\mathrm{Se}$ deficient rats it was shown that plasma levels of lipoproteins increase dramatically. In continuation of this study a quantitative microscopic study was undertaken to determine the behavior of myocardial interstitial tissue space (ITS) in $\mathrm{E}+\mathrm{Se}$ deficient rats as compared to control rats. Four rats fed on normal laboratory chow and 8 rats fed on basal diet supplemented with adequate $\mathrm{E}+\mathrm{Se}$ served as control. Eight rats were fed on $\mathrm{E}+$ Se deficient diet. The animals were sacrificed after 13 to 20 weeks. Qualitative microscopic study showed patchy areas of hemorrhage, edema, infiltration of macrophages and myocardial damage consisting of pyknosis and coagulation necrosis in the deficient rats. Quantitative microscopic study of the apparently normal areas of myocardium of deficient rats showed a shrinkage of ITS (21.0 \pm $1.29 \%$ vs $16.51 \pm 4.62 \%, \alpha=0.01$ ), whereas the ITS of normal laboratory chow and $\mathrm{E}+\mathrm{Se}$ supplemented groups were similar. The myocardial fiber diameter was unchanged. Using Starling's hypothesis regarding fluid movement across capillary walls, several mechanisms could be advanced to explain this apparently paradoxical phenomenon. We contend that the interstitial fluid of normal areas of the myocardium is either absorbed by the adjacent damaged areas, or before extravasation of the intravascular proteins and swelling of ITS, the interstitial fluid is first absorbed by the intravascular compartment, due to capillary membrane damage.
\end{abstract}

From the Department of Pediatrics, Meharry Medical College, Nashville, Tennessee.

Supported by Research Grant RR-08037-10 from the Division of Research Resources and the National Heart, Lung and Blood Institute.

Address for reprint: Jami G. Shakibi, M.D., 110 Bellevue Rd., Suite 9, Nashville, TN 37221 , U.S.A.

Received for publication October 24, 1985. 
Additional Indexing Words:

\begin{tabular}{|c|c|c|}
\hline Vitamin E & Selenium & Antioxidants \\
\hline
\end{tabular}

$\mathrm{V}$

ITAMIN E and selenium are two important antioxidants, whose presence in the diet of animals is important in preventing serious damage to organs such as brain, liver, skeletal muscles and the heart..1,2) The significance of selenium in humans was recently recognized. First the Chinese investigators reported on the importance of selenium in prevention of Keshan disease, a form of dilated cardiomyopahy, ${ }^{1), 3)}$ and subsequently sporadic cases were reported from other areas. ${ }^{4-6)}$ Both vitamin $\mathrm{E}$ and selenium are believed to exert their effects by preventing damage to the cell membranes and other subcellular membranes by lipid hydroperoxides. ${ }^{1,6), 7)}$ In a previous publication Stonc et al reported on the effect of vitamin $\mathrm{E}$ and Se deficiencies on the plasma lipoproteins. ${ }^{81}$ Here we report the responses of the myocardial interstitial tissue space (ITS) and myocardial fiber diameter (MFD) in the normal and deficient rats, using quantitative microscopy.

\section{Materials and Methods}

Sources of specimens

First experiment: Male inbred Fischer-344 rats from Charles River Breeding Laboratories, Wilmington, Massachusetts weighing 80-100 g were randomly divided into 3 dietary groups. The chow group (4 rats) was fed on a stock lab chow diet (Rodent Laboratory Chow 5001, Ralston Purina Co., St. Louis, Missouri). The B group (10 rats) was fed a Torula yeast based diet having very low levels of vitamin $\mathrm{E}$ and selenium, but adequate levels of all other nutrients. The $B+E+S e$ dietary group (10 rats) was fed a diet identical to the B group but supplemented with DL-alpha-tocopherol $(500 \mathrm{mg} / \mathrm{kg}$ of diet at I IU per $\mathrm{mg}$ of DL-tocopherol) and $0.4 \mathrm{ppm}$ Se (added as sodium selenite). All dietary supplies were purchased from U.S. Biochemical Co., Cleveland, Ohio. Rats were provided ad libitum the Torula yeast based diets and glass-distilled water to which $3 \mathrm{ppm}$ chromium (as $\mathrm{CrCl}_{3}$ ) was added. After 20 weeks on these diets the 4 lab chow rats, 4 rats from the $B$ dietary group and 4 of the $B+E+$ Se group were sacrificed and used for microscopic studies.

Second experiment: Male Fischer-344 rats were started on the experimental diets at a weight of 40-50 $\mathrm{g}$ in order to decrease the time required to establish vitamin $\mathrm{E}$ and/or selenium deficiencies. The rats were randomly divided (4 per group) into 4 dietary groups: $\mathrm{B} ; \mathrm{B}+\mathrm{E} ; \mathrm{B}+\mathrm{Se} ; \mathrm{B}+\mathrm{E}+\mathrm{Se}$. The $\mathrm{B}$ 
Table I. Myocardial Interstitial Tissue Space and Myocardial Fiber Diameter in 4 Laboratory Chow Rats, Group I

\begin{tabular}{c|c|c}
\hline & ITS $\%$ & MFD in microns \\
\hline 1 & 23.5 & 195.16 \\
$\# 11$ & 21.9 & 241.08 \\
$\# 6$ & 20.1 & 262.40 \\
$\# 21$ & 19.8 & 211.56 \\
Mean \pm ISD & $21.32 \pm 1.72$ & $227.55 \pm 30.01$
\end{tabular}

group received the basal vitamin $\mathrm{E}$ and selenium deficient diet. The $\mathrm{B}+\mathrm{E}$ received the basal diet supplemented with alpha-tocopherol, the $\mathrm{B}+\mathrm{Se}$ group received basal diet plus selenium supplement, whereas the $\mathbf{B}+\mathbf{E}+\mathrm{Se}$ group received supplements of both micronutrients. After 13 weeks the rats were sacrificed, and the hearts and other samples were fixed in 10\% formalin. Thus 3 groups of hearts were examined consisting of: Group I or Lab chow group: Four hearts of rats fed on laboratory chow. Group II or Group B+ E+Se: A total of 8 hearts, 4 from the first, and 4 from the second experiment, i.e. hearts from rats on vitamin $\mathrm{E}$ and selenium supplemented diet. Group III or Group B: A total of 8 hearts, 4 from the first and 4 from the second experiment, i.e. hearts of rats fed on basal diet, deficient in both vitamin $\mathrm{E}$ and selenium.

\section{Microscopic studies}

The hearts were fixed in 10\% formalin. The specimens were processed in standard fashion and embedded in paraffin. The blocks were sectioned and 5-micron thick sections were stained according to the Ehrlich's acid hematoxylin eosin method.93 The ventricular myocardium was first examined qualitatively. ITS and MFD were measured at sites in the left ventricular wall or ventricular septum where the myocardium appeared to be normal. ITS was measured by point counting technique on projected color slides on a screen. ${ }^{10)-12)}$ The slides were prepared from 5 randomly sampled areas of myocardium which appeared normal and where myocardial fibers were sectioned transversely using $\times 1000$ magnification under oil immersion objective. Myocardial fiber diameter (MFD) was measured on only those fibers which had nuclei situated in the center of the sectioned fibers. The longest diameter was measured on the projected slides from a fixed distance of the projector from the screen, using a 2.5 micron grid, for correction of magnification. A minimum of five MFD's were measured for each heart. The ITS's and MFD's were averaged and taken as representative value for each specimen. Thus, each value presented in Tables I, II and III represents a mean value of 
Table II. Myocardial Interstitial Tissue Space and Myocardial Fiber Diameter in 8 Rats Fed on Basal Diet Deficient in Vitamin E and Selenium Supplemented with Vitamin $\mathrm{E}$ and Selenium, Group II

\begin{tabular}{c|c|c}
\hline & ITS $\%$ & MFD in microns \\
\hline \#34 & 19.6 & 227.96 \\
$\# 28$ & 19.9 & 226.32 \\
$\# 4$ & 20.4 & 217.30 \\
$\# 9$ & 22.1 & 231.24 \\
\#14 & 22.6 & 295.20 \\
\#24 & 20.6 & 223.04 \\
\#69 & 21.6 & 280.44 \\
\#54 & 19.9 & 219.76 \\
Mean ISD & $20.83 \pm 1.12$ & $240.15 \pm 30.00$ \\
Mean ISD of Groups & $21.0 \pm 1.29$ & $235.95 \pm 29.27$ \\
I II combined & &
\end{tabular}

Table III. Myocardial Interstitial Tissue Space and Myocardial Fiber Diameter in

9 Rats Fed on Basal Diet, i.e., Vitamin E and Selenium Deficient Diet, Group III

\begin{tabular}{c|c|c}
\hline & ITS $\%$ & MFD in microns \\
\hline 5 & 11.25 & 243.54 \\
$\# 10$ & 13.7 & 351.78 \\
$\# 15$ & 14.6 & 256.66 \\
$\# 30$ & 22.5 & 292.74 \\
$\# 35$ & 20.0 & 233.70 \\
$\# 45$ & 15.2 & 223.86 \\
$\# 70$ & 22.7 & 237.80 \\
$\# 25$ & 12.2 & 213.20 \\
Mean 1 ISD & $16.5 \pm 4.62$ & $256.66 \pm 45.30$
\end{tabular}

five different sites randomly sampled for quantitative study. Group I was tested vs Group II and combined Groups I and II were tested against Group III, using one-way ANOVA method..$^{13}$

\section{RESULTS}

Qualitative microscopic study revealed patchy areas of lesions interspersed with normal myocardium in all specimens obtained from Group III, i.e., rats with vitamin $\mathrm{E}$ and selenium deficiency. The lesions consisted of edema, interstitial hemorrhage, pyknosis and infiltration with macrophages and proliferation of fibroblasts (Figs. 1, 2). Occasional areas of coagulation necrosis were noted. Some specimens showed perivascular lesions. The results of ITS and MFD measurements on the 3 groups are shown in Tables I, 


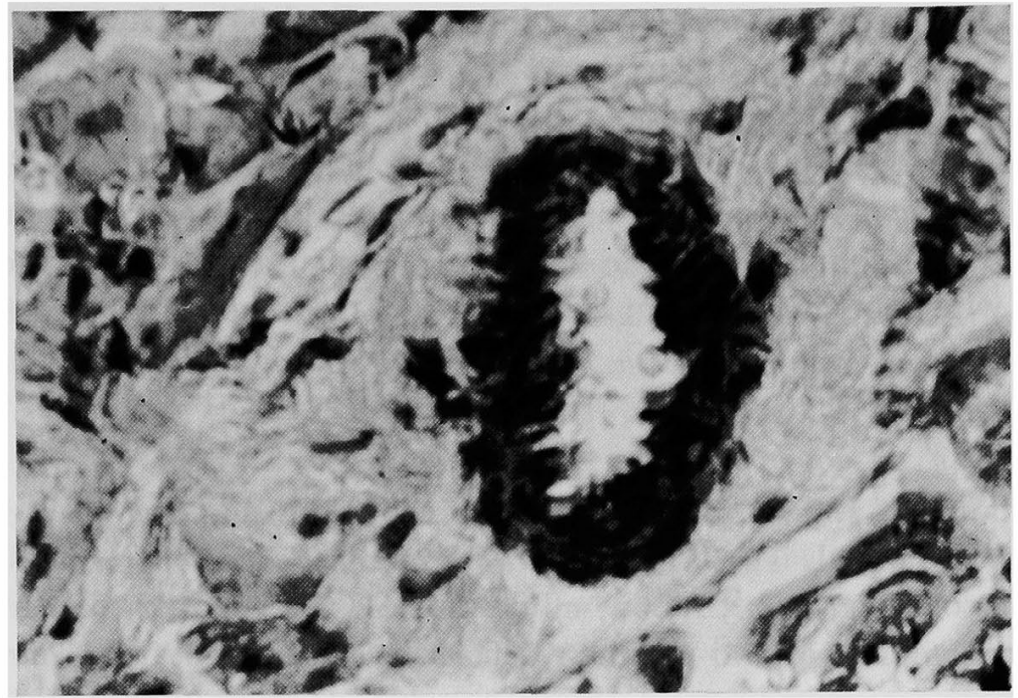

Fig. 1. Perivascular edema and infiltration with fibroblasts. (H \& E, Oil immersion, $\times 1000)$

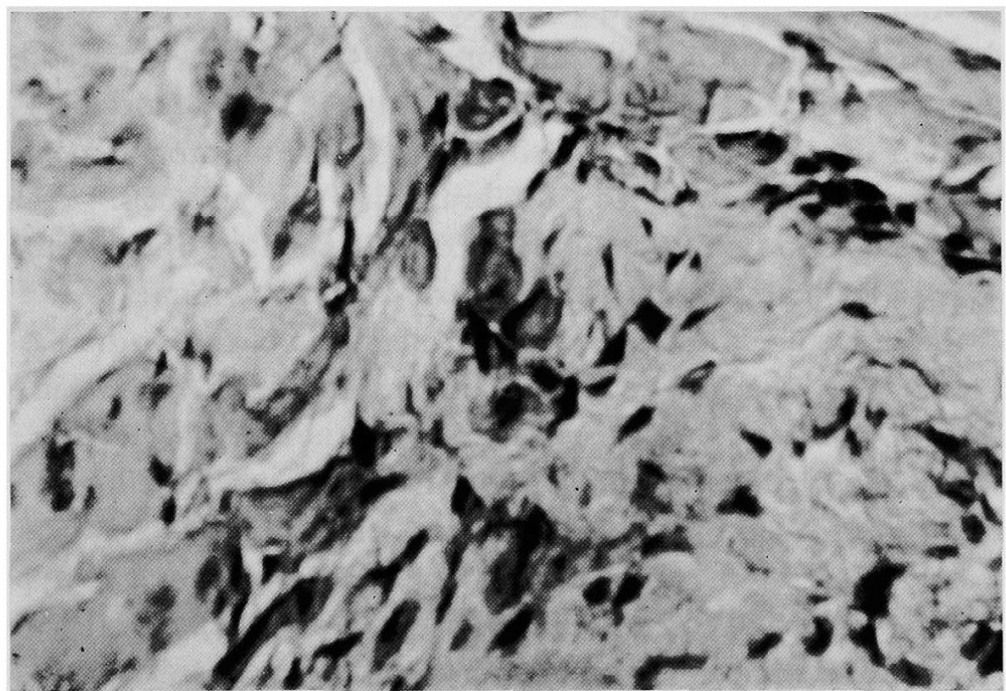

Fig. 2. A large area of fibrosis with normal myocardial fibers at the top and to the left. (H \& E, Oil immersion, $\times 100)$

II and III.

A statistical comparison between Group I and Group III using ANOVA method showed no difference ( $F=0.032$ for ITS and $F=0.470$ for MFD). Therefore data from Groups I and II were pooled and compared with Group III. The analysis of data showed that MFD in Group III is not different 
from the normal and supplemented groups $(F=1.55)$. However ITS in Group III was significantly less than ITS in combined Groups I and II. The critical value for $\alpha=0.05$ and $\alpha=0.01$ are 4.41 and 8.29 , respectively. Since our observed $\mathrm{F}=10.90$ is more than both $\alpha=0.05$ and $\alpha=0.01$ critical values, there is sufficient evidence to show that population means are not equal. Thus ITS was contracted in the apparently normal areas of myocardium in the rats with combined nutrient deficiency.

\section{Discussion}

Vitamin $\mathrm{E}$ and selenium are two antioxidants whose role in prevention of disease in animals is well recognized. Vitamin E deficiency causes disease in the bovine, pig, horse, rabbit, mink, chicken, duck, turkey and trout. ${ }^{1,6)}$ Combined vitamin $\mathbf{E}$ and selenium deficiency causes myocardial damage in swine, sheep, cattle and poultry. ${ }^{3), 6)}$ The role of selenium was not recognized in man until recently when the Chinese investigators showed that selenium deficiency is one of the principal factors responsible for Keshan disease, a dilated cardiomyopathy, affecting mainly children and young women, living in rural areas of selenium-deficient zones in China. ${ }^{3)-5)}$ Sporadic cases of cardiomyopathy due to selenium deficiency have been reported elsewhere. ${ }^{3)}$ The disease in the animals and the clinical signs are variable depending upon the organ most severely affected, i.e., brain, liver, or muscles. ${ }^{11}$ The lesions vary in intensity even within a single species, depending upon factors such as age, and physiological state. ${ }^{2)}$ Combined deficiency of vitamin $\mathrm{E}$ and selenium increases the incidence of disease. Thus selenium deficiency increases the incidence of fatal myocarditis in mouse pups infected with Coxsackie B virus. $\left.{ }^{4}\right)$

Recently, more attention has been paid to the role of selenium in pathogenesis of coronary disease and hyperlipidemia in man. Thus it has been shown that serum levels of selenium is decreased by ethanol and cigarette use, and this is possibly the mechanism of the relation of selenium to hypertension and atherosclerosis. ${ }^{14)-16)}$ Finland and New Zealand, 2 countries with low dietary intake of selenium, have exceptionally high cardiovascular mortality. $\left.{ }^{16}\right)$ It is probable that selenium and vitamin $\mathrm{E}$ are protective against cardiovascular disease. Stone et al had previously reported from this laboratory increased serum lipoproteins in vitamin $\mathbf{E}$ and selenium deficient rats. ${ }^{8}{ }^{8}$

At the present state of our understanding, it is believed that both vitamin $\mathrm{E}$ and selenium exert their beneficial effects by counteracting hyperoxide damage to cell membranes, though through different mechanisms. Thus, whereas vitamin $\mathrm{E}$ is believed to prevent formation of lipid hyperoxides by prevention of propagation of free oxygen radicals that peroxidize membrane 
lipids, ${ }^{1,17), 18)}$ selenium is believed to destroy lipid hydroperoxides by being an integral component of the enzyme glutathione peroxidase, ${ }^{11,6), 7), 151,18)}$ which destroys H202 and lipid hydroperoxides which damage the phospholipids of membranes, ${ }^{6,7)}$ including the cell membranes as well as various subcellular membranes composing mitochondria and the microsomal fraction of the cell. ${ }^{71}$ Pathology in the skeletal muscles and myocardium due to vitamin $\mathrm{E}$ and selenium deficiency has been reported by several authors. Classically, selenium deficiency causes " mulberry heart disease" in cattle due to extensive cardiac hemorrhage. ${ }^{11,2)}$ The myocardial lesions are patchy and diseased myocardium may lay side by side with normal tissue. The reason for the apparent immunity of some cells to pathology in the same organ is not known. ${ }^{1,2)}$ The pathological lesions reported previously in animals deficient in selenium are segmental, ranging from fiber necrosis to vascular damage to myocardial arterioles and capillaries. ${ }^{1,2)}$ Myocardial damage due to selenium deficiency in man consists of myocytolysis, fibrosis, hyaline necrosis, accumulation of droplets of lipofuscin-like pigment in Purkinje fibers, followed by necrosis, hyalinized fibers, pyknotic nuclei, invasion by macrophages and fibrosis. ${ }^{1,3)-6)}$ Ultrastructural studies have shown that myocardial fiber lesions and fibrosis are independent of vascular lesions. The vascular lesions consist of segmental fibrinoid accumulation in vessel walls and scattered fibrin thrombi. Endothelial cells are initially loosely attached and in the more seriously injured areas they are totally disrupted with insudation of blood proteins into the vessel wall. ${ }^{2}$ Our study was aimed at a quantitative appraisal of the apparently normal myocardium in the hearts of rats deficient in vitamin $\mathrm{E}$ and selenium. In this study it was found that the normal areas of myocardium in the deficient specimens are characterized by a significant contraction of the ITS. Since the mean MFD was unchanged, the reduction of the ITS could not be due to increased MFD, Considering the basic pathophysiology of myocardial damage in selenium deficiency one would have expected an increase in the ITS. However, although this is the case in the damaged areas, the normal areas had less ITS.

ITS consists primarily of interstitial fluids bathing the cells. According to Starling's hypothesis-fluid movement $=\mathrm{K}\left(\mathrm{P}_{\mathbf{c}}+\mathrm{II}_{\mathbf{i}}\right)-\left(\mathrm{P}_{\mathbf{i}}+\mathrm{II}_{\mathbf{p}}\right)$. For the ITS to decrease either $\left(P_{c}+I_{i}\right)$, i.e., the filtering force must decrease or $\left(P_{i}\right.$ $+\mathrm{II}_{\mathbf{p}}$ ), i.e., the absorbing force must increase. Moreover, the factor $\mathrm{K}$, i.e., the filtration constant of the capillary membrane must be considered. ${ }^{19}$ Although we do not have data to support or refute any of the above mechanisms, the basic pathophysiological lesion in vitamin $\mathrm{E}$ and selenium deficiency, i.e., damage to the capillary endothelial membrane leads us to believe that the ITS decreased in the "normal myocardium" due to one of the following 
factors:

1) Either the interstitial fluid of the normal areas of the myocardium is absorbed by the adjacent diseased areas having a higher oncotic pressure, thus contributing to their edema, or 2) Before the capillary endothelial damage is severe enough to allow plasma proteins to escape the capillary membrane into the ITS, the interstitial fluids are absorbed by the intravascular compartment, thus leading to its contraction. Once the damage is severe enough, the proteins extravasate and attract fluids to the ITS.

A similar unpublished study on the intertubular space of the renal cortices of these rats has also shown a contraction of the ITS in the apparently normal renal cortices of deficient rats.

\section{ACKNowledgments}

We wish to thank Ms. Hermaline Turner for her secretarial assistance, and Ms. Elizabeth Stewart and Mr. Asghar Kheshti for their cooperation in this work. Also, we wish to thank B. Moezzi, Ph.D. for the statistical analysis of the data.

\section{REFERENCES}

1. McMurray CH, Rice DA, Kennedy S: Experimental models for nutritional myopathy. Ciba Found Symp 101: 201, 1983

2. Van Vleet JF, Ferrans VJ, Ruth GR: Ultrastructural alterations in nutritional cardiomyopathy of selenium-vitamin E deficient swine. II. Vascular lesions. Lab Invest 37: 201, 1977

3. Johnson RA, Baker SS, Fallon JT, Maynard EP, Ruskin JN, Wen Z, Ge K, Cohen HJ: An accidental case of cardiomyopathy and selenium deficiency. New Engl J Med 304: 1210, 1981

4. Editorial: Selenium perspective. Lancet 2: 685, 1983

5. Sartiano GP, Lynch WE, Hopkins CB, Darby TD: Erythrocyte and plasma selenium measurements in congestive cardiomyopathy. New Engl J Med 307: 558, 1982

6. Fleming CR, Lie JT, McCall JT, O'Brien JF, Baillie EE, Thistle JL: Selenium deficiency and fatal cardiomyopathy in a patient on home parenteral nutrition. Gastroenterology 83: 689,1982

7. Combs GF, Noguchi T, Scott ML: Mechanisms of action of selenium and vitamin $\mathbf{E}$ in protection of biological membranes. Fed 34: 2090, 1975

8. Stone WL, Stewart ME, Nicholas C, Pavoluri S: Effects of dietary selenium and vitamin E on plasma lipoprotein-cholesterol levels in male rats. Ann Nutr Metab 30: 94, 1986

9. Smith A, Burton J (eds): A Color Atlas of Histological Staining Techniques, Wolfe Medical Publications Ltd, London, p 123, 177-185, 1977

10. Shakibi JG, Aryanpur I, Nazarian I: The anatomic correlate of ventricular dysfunction in tetralogy of Fallot. Jpn Heart J 20: 53, 1979

11. Fuster V, Danielson MA, Robb RA, Broadbent JC, Brown AL Jr, Elveback L: Quantitation of left ventricular myocardial hypertrophy and interstitial tissue in human hearts with chronically increased volume and pressure overload. Circulation 55: 504, 1977

12. Weibel RR, Kistler GS, Scherle WF: Practical stereological method for morphometric cytology, J Cell Biol 30: 23, 1966

13. Duncan RC, Knapp RG, Miller MC III (eds): Introductory Biostatistics for the Health 
Sciences, John-Wiley and Sons, NY, p 119-125, 1977

14. Lund DD, Tomanek RJ: Myocardial morphology in spontaneously hypertensive aortic constricted rats. Am J Anat 152: 141, 1978

15. Moore JA, Novia R, Wells IC: Selenium concentrations in plasma of patients with arteriographically defined coronary atherosclerosis. Clin Chem 30: 1171, 1984

16. Salonen JT, Alfthan G, Huttunen JK, Pikkarainen J, Puska P: Association between cardiovascular death and myocardial infarction and serum selenium in a matched pair longitudinal study. Lancet 2: 175, 1982

17. Lorch V, Murphy MD, Hoersten LR: Unusual syndrome among premature infants: association with a new intravenous vitamin E product. Pediatrics 75: 598, 1985

18. Hoekstra WG: Biochemical function on selenium and its relation to vitamin E. Fed Proc 34: 2083, 1975

19. Berne PM, Levey MN (eds): Cardiovascular Physiology, Fourth Edition, GV Mosby, St. Louis, p 114-120, 1981 